\title{
Hydrocephalus Complicating Dementia
}

\author{
Authors \\ Sushma Viswanathan ${ }^{1}$, Swetha Raghavan ${ }^{2}$, Pranjali Bansal ${ }^{3}$, Sathianathan $\mathbf{R}^{4}$ \\ ${ }^{1}$ Assistant Professor, ${ }^{2}$ Senior Resident, ${ }^{3}$ Junior Resident, ${ }^{4}$ Professor \\ Department of Psychiatry, Sri Ramachandra University, Porur, Chennai-600 116, Tamil Nadu, India \\ Corresponding Author \\ Dr Swetha Raghavan \\ Senior Resident, Department of Psychiatry \\ No. 1 Sri Ramachandra Nagar, Porur, Chennai -600 116 Tamil Nadu India \\ Contact No: +91 9962530388, Email:drraghaswe@yahoo.co.in
}

\begin{abstract}
Dementia as a disorder has existed since time immemorial. Hydrocephalus cases were described by Hippocrates, Galen and several others who believed that extra cerebral accumulation of water caused it [1]. It was Salomon Hakim who first described the syndrome of Normal Pressure Hydrocephalus (NPH) in $1957^{[2]}$. Despite such vast evidence at the present time, there is dearth of literature regarding the cooccurrence of Dementia and subsequent NPH. Hence we present here, the case of a 67 year old teacher who suffered a similar event and eventually improved.
\end{abstract}

Keywords-Dementia, Hydrocephalus, Normal Pressure Hydrocephalus.

\section{Introduction}

Progressive deterioration of central nervous system (CNS) pathologies may present variedly and may often co-occur than not. Two different diagnostic entities occurring at different periods in time, necessitates detailed evaluation and tailored management for better outcomes of both the disorders.

This case discussed here teaches us a lesson that it is unscientific to label patient's symptoms to any existing primary proven disease pathology. As clinicians we always need to be watchful and updated with existing scientific literature in our respective areas of specialization.

\section{Case Presentation}

A retired school headmaster, of Asian origin, in her late sixties was brought by her husband to the psychiatry outpatient department with history of forgetfulness noticed since past 3 years.

Our patient was a very responsible and workaholic individual. She had two sons who lived overseas and she interacted with them regularly over the phone. She indulged in all household chores which included cooking, cleaning, washing etc on her own. She frequented temples, took part in religious gatherings and also involved herself in maintaining banking related activities.

Around 3 years back, her husband noticed that patient was often seen searching for things like keys, spectacles, newspaper etc. She was found preoccupied with her forgetfulness and would lament about not being able to recall names of relatives, feeling helpless about her worsening cooking skills. On few occasions she failed to take 
the cheque book to the bank. She was seemingly becoming confused about navigation outside and within her apartment. She also began experiencing sleep disturbances, in the form of difficulty in initiating and maintaining her sleep. Over the span of next 2 years self care, household responsibility declined and she then had a house maid for her assistance for almost all activities including cooking, toileting etc. After 2 years of such memory lapses she was taken to a neurologist and started on $5 \mathrm{mg}$ Donepezil. Imaging studies (MRI Brain) revealed diffuse cerebral atrophy, small vessel disease with gliotic changes in right medial temporal lobe. The dose of Donepezil was titrated to a maximum of 10 mg daily; however she continued to deteriorate at a slow pace.

Towards the end of 2016, patient was noticed to display disinhibited behaviour being inadequately dressed at times; swaying sideways excessively while walking and frequent episodes of bed-wetting. After a trivial fall in her house, she received inpatient medical attention for a period of 5 days. CT Brain plain done at this time was normal. She was hence discharged with Donepezil $10 \mathrm{mg}$ once daily. Over the next 3 months, patient often became irritable but managed herself with help from her domestic maid.

It was in March 2017, she was brought to our department of psychiatry with complaints of forgetfulness, irritability, getting angry over trivial issues, refusal to eat food and bladder incontinence. During this evaluation it was deciphered that again around a fortnight before these symptoms began, patient had a trivial fall in her bathroom, however she did not suffer any major trauma. At the time of examination patient was conscious, oriented but however she had difficulty in recalling recent events or retaining new information. She also endorsed infrequent auditory hallucinations of an unknown male voice calling out her name. Neurological examination in the emergency room (ER) was unremarkable, except for gait imbalance. She could not stand or walk unaided. Patient was then investigated with an urgent MRI Brain which revealed disproportionate dilatation of lateral, third ventricles and sylvian cisterns in comparison to cerebral atrophy - suggestive of normal pressure hydrocephalus. With a provisional diagnosis of Dementia with behavioural disturbances with secondary normal pressure hydrocephalus, patient was admitted under department of psychiatry for management of behavioural issues. A consultationliaison team was formed with a primary psychiatrist, behavioural therapist and a secondary neurologist and neurosurgical specialist, for holistic treatment. Initially patient was evaluated by a general physician for management of electrolyte imbalance as patient had poor nutritional intake in the past week. Neurologist consult was obtained for optimization of dose of donepezil. Her behavioural problems were managed with low dose of haloperidol and benzodiazepines were used for sedation. Neurosurgeons suggested a wait and watch approach to see if symptoms related to hydrocephalus worsened as they felt that lumbar puncture might not be required at that moment.

\section{Investigations}

During the current admission complete hemogram, liver parameters, renal function test, thyroid function test and lipid profile were found to be normal. Imaging studies included the following: 1)EEG: was normal and 2) MRI Brain plain showed disproportionate dilatation of lateral , third ventricles and sylvian cisterns in comparison to cerebral atrophy - suggestive of normal pressure hydrocephalus.

\section{Psychometry}

The following assessments were done:

- Mini mental status examination was done with total score of 20 , showing moderate degree of impairment, requiring 24 hour supervision.

- Hamilton depression rating scale was administered, total score was 19 , falling into moderate category

Since patient was uncooperative, detailed neuropsychological assessment of dementia could not be done. 


\section{Diagnosis}

After an initial evaluation in the ER a provisional diagnosis of F00 Dementia with behavioural disturbances was made. However, after detailed clinical evaluation, and examination and on the basis of MRI brain findings, diagnosis was revised to ICD 10 diagnosis F00.1 Dementia, late onset complicated with normal pressure hydrocephalus.

\section{Treatment}

During in-patient stay our patient received intravenous fluids and parenteral nutrition to improve her nutritional state. She was ambulated frequently with help from physiotherapists. Low dose of $1.5 \mathrm{mg}$ Haloperidol was used to help with behavioural problems. Injectable lorazepam of $1 \mathrm{mg}$ was used on PRN basis if patient was restless or sleep deprived. Donepezil 5mg twice daily was continued as per neurophysician suggestion. With the above regimen, patient showed dramatic improvement over the next four days. There after patient was trained to use a call bell every time she desired to go to the restroom. This helped her to achieve a sense of control over her bladder habits. By about fifth day, she had begun to feed and dress herself. Re-orientation strategies including a huge clock, a calendar, daily newspaper were used to keep her on track with outside events. At the time of discharge on day 7 , she was well behaved, oriented and walked by herself unaided to the parking area. Haloperidol was tapered and stopped and patient was discharged with $5 \mathrm{mg}$ of Donepezil twice a day along with 25mg of Quetiapine at night.

\section{Outcome and Follow Up}

The patient was reviewed one week post discharge. She showed remarkable change in her behaviour and communication. She had started walking unaided, bladder control had been achieved. Though her deficits with regards to recent events persisted, she seemed to be more actively involved with her spouse and children. She was advised to continue $10 \mathrm{mg}$ of Donepezil and 25mg of Quetiapine at night time and to come for monthly visits.

\section{Discussion}

Few recent studies have shown coexistence of Alzheimer's disease and adult onset chronic hydrocephalus, also called as normal pressure hydrocephalus (NPH) ${ }^{[3,4 \text {, and 5] }}$. Gerald D Silverberg et al (2003) proposed a common physiological basis in cerebrospinal fluid dynamics, failure as a course for both the disorders namely Alzheimer's disease and normal pressure hydrocephalus ${ }^{[7]}$. Two changes in CSF circulation occur as a part of normal ageing.

1. Lower CSF production, hence decrease in CSF turnover and

2. Greater resistance to CSF outflow.

Gerald et al ${ }^{[7]}$ hypothesized that all else being static, the initially dominant physiological change determined whether CSF circulatory failure manifested as Alzheimer's disease or as normal pressure hydrocephalus. If CSF production failure dominated Alzheimer's disease will occur, while if resistance to CSF outflow predominates Normal Pressure hydrocephalus results. Failure of CSF to clear potentially toxic metabolites would lead to accumulation of Amyloid-B peptide, microtubular associated protein $\mathrm{T}$ (MAP- T) and subsequent Alzheimer's disease at a later date.

In our patient, probably the first hypothesis occurred initially resulting in dementia symptoms in the beginning. Repeated subsequent trivial falls might have accentuated the failure in absorption of CSF, which then manifested as Normal Pressure hydrocephalus.

Relkin et al (2005) ${ }^{[6]}$ classified the likelihood of normal pressure hydrocephalus being present as probable, possible and unlikely depending on the history, physical findings and supporting studies. The patient described here met the criteria for possible hydrocephalus. Considering previous literature on response to large volume lumbar puncture, patient was managed conservatively and she improved significantly at the time of discharge. Hence this reiterates the fact that better knowledge of co-occurrence of hydrocephalus with other CNS disorders shall help in improving patient's outcome. 


\section{Learning Points}

- Similar presentation of varied disorders is important to be watched for in every patient

- Do not ignore any new complaints attributing it to existing disease pathology

- Better knowledge of co-existing disorders might improve patient outcomes.

\section{Source of Support: Nil}

\section{Conflict of Interest: None}

\section{References}

1. Aschoff A, Kremer P, Hashemi B, Kunze S. The scientific history of hydrocephalus and its treatment. Neurosurg Rev. 1999 Oct;22(2-3):67-93; discussion 94-5

2. Wallenstein MB, McKhann GM. Salomon Hakim and the discovery of normal-pressure hydrocephalus. Neurosurgery. 2010 Jul;67(1):155-9; discussion 159

3. Del Bigio MR, Cardoso ER, Halliday WC. Neuropathological changes in chronic adult hydrocephalus: cortical biopsies and autopsy findings. Can J Neurol Sci 1997; 24: 121-26

4. Savolainen S, Paljarvi L, Vapalahti M. Prevalence of Alzheimer's disease in patients investigated for presumed normal pressure hydrocephalus: a clinical and neuropathological study. Acta Neurochir (Wien) 1999; 141: 849-53

5. Golomb J, Wisoff J, Miller DC, et al. Alzheimer's disease comorbidity in normal pressure hydrocephalus: prevalence and shunt response. J Neurol Neurosurg Psychiatry 2000; 68: 778-81

6. Relkin N, Marmarou A, Klinge P, et al. 2005. Diagnosing idiopathic NPH. Neurosurgery, 57 (3 suppl) : 54-16

7. Gerald DSilverberg ${ }^{\mathrm{a}}$, MarthaMayo ${ }^{\mathrm{b}}$, Thomas Saul $^{c}$, EdwardRubenstein ${ }^{\mathrm{a}}$, DawnMcGuire ${ }^{\mathrm{bc}}$. The lancet, Neurology, Volume 2, Issue 8, August 2003, Pages 506-511. 